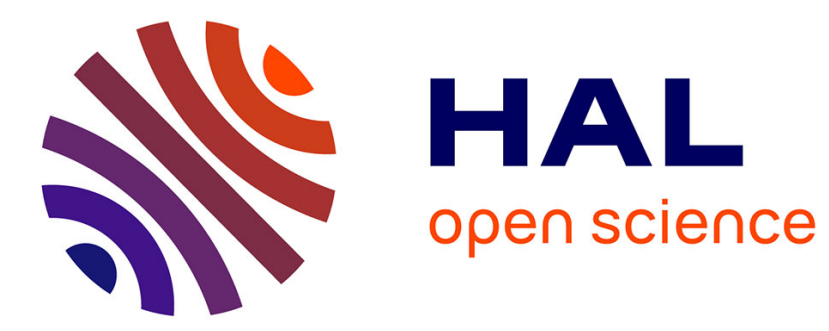

\title{
Parameter-Based Rules for the Definition of Detectable Ducts for an RFC System
}

Rémi Douvenot, Vincent Fabbro, Kevin Elis

\section{To cite this version:}

Rémi Douvenot, Vincent Fabbro, Kevin Elis. Parameter-Based Rules for the Definition of Detectable Ducts for an RFC System. IEEE Transactions on Antennas and Propagation, 2014, Nov. 2014, 62 (11), pp 5696-5705. 10.1109/TAP.2014.2354680 . hal-01066817

\section{HAL Id: hal-01066817 https://hal-enac.archives-ouvertes.fr/hal-01066817}

Submitted on 22 Sep 2014

HAL is a multi-disciplinary open access archive for the deposit and dissemination of scientific research documents, whether they are published or not. The documents may come from teaching and research institutions in France or abroad, or from public or private research centers.
L'archive ouverte pluridisciplinaire HAL, est destinée au dépôt et à la diffusion de documents scientifiques de niveau recherche, publiés ou non, émanant des établissements d'enseignement et de recherche français ou étrangers, des laboratoires publics ou privés. 


\title{
Parameter-Based Rules for the Definition of Detectable Ducts for an RFC System
}

\author{
Rémi Douvenot, Vincent Fabbro, and Kevin Elis
}

\begin{abstract}
Refractivity from clutter (RFC) consists in inferring the lower atmospheric conditions from the clutter measured by a coastal or shipborne radar. A data processing tool based on an inverse or optimisation method is required. However, RFC cannot be used to retrieve all the atmospheric conditions. For some refractivity conditions, the modification of the electromagnetic wave behaviour in the low troposphere is not detectable on the radar clutter return. In this article, analytic conditions are given for trilinear atmospheric ducts to be retrievable by an RFC system. The study is based on a ray approach, and the results are validated through numerical simulations. It is finally extended to any piecewise linear profile. In the context of decision analysis, an RFC system user should know which ducts can be detected.
\end{abstract}

Index Terms-Refractivity from clutter, ray tracing, atmospheric duct, inverse problem.

\section{INTRODUCTION}

$\mathbf{F}$ OR years, efforts have been made to infer the behaviour of the electromagnetic waves in the low troposphere. The aim is to make accurate estimations of the radar range in coastal or open sea environment. This can be performed by in situ meteorological measurements with buoys and rocketsondes. A bulk model is applied to deduce the refractive index from the meteorological data [1]-[3]. This method requires substantial additional equipment and time for proceeding to the measurements. It is still in use today even if not appropriate for a real-time description of the low troposphere.

Mesoscale numerical weather prediction models provide statistics of the meteorological conditions depending on the time and location. These statistics can be used for the forecast of occurrence and type of atmospheric ducts [4]. The atmospheric conditions can also be inferred with the low elevation GPS satellites [5]. An atmospheric duct bends the electromagnetic waves, which can be detected through the measured flight time. These two methods are easy to take on board in operational conditions. However, they can only give a coarse description of the troposphere.

The low troposphere can also be inferred by inverse methods applied to in situ electromagnetic measurements. Refractive index conditions have been retrieved with a matched-field method from point-to-point UHF measurements performed

The presented work has been carried out in the framework of the FrenchGerman Technical Agreement 119 : "Modelling and measurements of sea clutter at centimetre and millimetre bands; application to atmospheric refractivity assessment" involving FHR, WTD71, DGA-MI, and ONERA.

Rémi Douvenot is with the TELECOM/EMA department, ENAC, Toulouse Univ., 31055 Toulouse, France, e-mail: remi.douvenot@ recherche.enac.fr.

Vincent Fabbro is with the DEMR department, ONERA, 31055 Toulouse, France, e-mail: vincent.fabbro@ onera.fr

Kevin Elis was with the TELECOM/EMA department, ENAC, Toulouse Univ., 31055 Toulouse, France. He is now with the Antenna department, CNES, 31401 Toulouse, France, e-mail: kevin.elis@cnes.fr during the VOCAR experiment [6]-[9]. More recently, a matched-field approach has been performed in a bistatic configuration, the field being measured by an array of radio receivers [10]. This method requires both a transmitter and a receiver. Consequently, this is useful for very specific conditions and for validation purposes.

Refractivity from clutter (RFC) techniques [11] fills in this gap. The basic idea is to deduce the trajectory of the electromagnetic wave by the large-scale variations in the clutter measurements in a monostatic configuration. Indeed, a trapping layer can significantly increase the range of a radar and create blind spots above this latter. They are easily detected by looking at the clutter map, but RFC consists in quantifying these atmospheric conditions.

Retrieving the duct conditions from the clutter measurements is a nonlinear and ill-posed inverse problem. Many techniques have been proposed for performing RFC. Usually, the duct is described with few parameters that can be retrieved by, among others, genetic algorithm [12], hybrid genetic algorithm-Markov chain Monte Carlo method [13], Kalman and particle filters [14], least-squares support vector machines [15], improved nearest neighbour approach [16], [17]. Methods have also been proposed with non-parametric atmospheric profiles retrieved by variational adjoint approach [18]. A detailed and complete overview on RFC is available in [19]. More recently, the merging of RFC and mesoscale models has been proposed [20].

In this article, the problem of which ducts can be retrieved by an RFC system is addressed. Indeed, some ducts have no effect on the clutter data itself in the radar range. For instance, a too high trapping layer bends the electromagnetic wave that reaches the sea surface after the radar maximum range. Consequently, it cannot be detected. More generally, we define a retrievable duct as a duct for which a slight variation of any of its parameter leads to a modification in the measured clutter data before the maximum radar range. Indeed, the retrievability of a duct does not only depend on its base height. Analytic conditions on the duct parameters are given for trilinear profiles, but the method can be applied to any piecewise linear duct. The goal is twofold: anticipating which duct can be retrieved by an RFC system, and sizing measurement campaigns from desired retrieved ducts. Numerical simulations show the relevancy of the approach.

Section II introduces a ray study where trajectories in the presence of trilinear atmospheric ducts are presented. The geometric variables are exposed and the relations between range, elevation angle, and the duct parameters are stated. In section III, the ray study is used to define the ducts retrievable by RFC. Several scenarii are taken into account, depending 
on the duct parameters and antenna height. In section IV, numerical simulations of retrievable and non-retrievable ducts validate the study. Moreover, the presented rules are applied to the measurements from the previous RFC works. In section $\mathrm{V}$, the method is extended to take into account an evaporation duct and, more generally, any piecewise linear profile. Finally, the conclusion is exposed in section VI.

All the wave propagation simulations are based on the parabolic approximation of the Helmholtz equation solved by a split-step Fourier algorithm [21], [22]. The mean sea surface is considered smooth and perfectly conducting, and the propagation factor is taken at $1 \mathrm{~m}$ high. Then, the main variation of the sea clutter with the grazing angle is included in the propagation factor [16]. Note that the propagation factor is theoretically null at altitude $z=0$.

\section{RAY STUDY}

This section introduces a ray-tracing study for the characterisation of the non-retrievable ducts. In this study, the ducts are supposed constant with the distance.

In the following developments, the case of the antenna below the trapping layer and inside the trapping layer are studied. The notations $x^{\mathrm{b}}$ and $x^{\mathrm{i}}$ denote the value $x$ calculated in the case of the antenna below and inside the trapping layer, respectively.

The study is based on the trajectory equation that is expressed for low angles as [23]

$$
M-\frac{\theta^{2}}{2}=\mathrm{C}^{\mathrm{st}},
$$

where $M$ is the modified refractivity in M-unit, $\theta$ is the angle of the ray trajectory with the horizontal $(\theta \ll 1 \mathrm{rad})$, in milliradians, and $\mathrm{C}^{\text {st }}$ is a constant value.

\section{A. Trilinear duct with infinite thickness}

A bilinear duct is first supposed, as represented in figure 1 . It stands for a trilinear duct with a trapping layer of infinite thickness. $z_{\mathrm{b}}$ is the trapping layer base height, $c_{0}$ is the slope of refractivity below the trapping layer, and $c_{2}$ is the slope of refractivity inside the trapping layer. The slope $c_{0}$ is chosen equal to $0.118 \mathrm{M}$-unit. $\mathrm{m}^{-1}$, which corresponds to the standard atmosphere. For a fixed elevation angle $\theta_{0}$, the distance $x_{\text {reach }}$ at which the ground is reached can be calculated.

1) Antenna below the trapping layer: The trapping layer base height $z_{\mathrm{b}}$ is assumed greater than the antenna height $h_{\text {ant }}$. Then, the ray follows a trajectory depicted in figure 2 . $\theta_{0}^{\mathrm{b}}, \theta_{1}^{\mathrm{b}}, \theta_{2}^{\mathrm{b}}$, and $\theta_{3}^{\mathrm{b}}$ are the angles between the horizontal and the trajectory at the distances $x_{0}^{\mathrm{b}}=0, x_{1}^{\mathrm{b}}, x_{2}^{\mathrm{b}}$, and $x_{\text {reach }}^{\mathrm{b}}$, respectively. We write

$$
x_{\text {reach }}^{\mathrm{b}}=x_{1}^{\mathrm{b}}+\left(x_{2}^{\mathrm{b}}-x_{1}^{\mathrm{b}}\right)+\left(x_{\text {reach }}^{\mathrm{b}}-x_{2}^{\mathrm{b}}\right) .
$$

Under the assumption $\left|\theta_{0}\right| \ll 1$, the first distance is expressed as [24]

$$
x_{1}^{\mathrm{b}}=\frac{\theta_{1}^{\mathrm{b}}-\theta_{0}^{\mathrm{b}}}{c_{0}},
$$

with

$$
\theta_{1}^{\mathrm{b}}=\sqrt{\theta_{0}^{\mathrm{b}^{2}}+2 c_{0}\left(z_{\mathrm{b}}-h_{\mathrm{ant}}\right)} .
$$

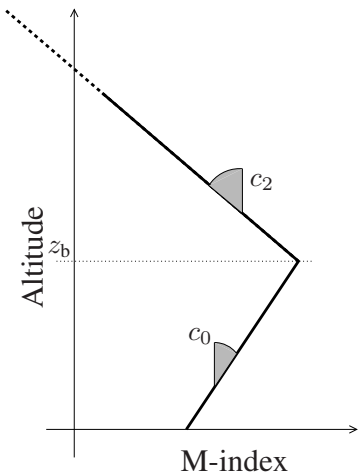

Fig. 1. The trilinear duct with a trapping layer of infinite thickness.

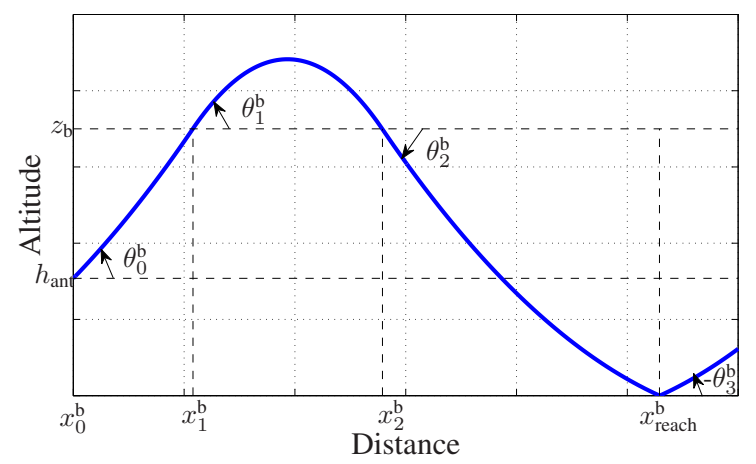

Fig. 2. Trajectory of a ray in the presence of a trilinear duct with a trapping layer of base height $z_{\mathrm{b}}$ and infinite thickness, case $h_{\mathrm{ant}}<z_{\mathrm{b}}$.

The distance $x_{2}^{\mathrm{b}}-x_{1}^{\mathrm{b}}$ is given by

$$
x_{2}^{\mathrm{b}}-x_{1}^{\mathrm{b}}=\frac{\theta_{2}^{\mathrm{b}}-\theta_{1}^{\mathrm{b}}}{c_{2}},
$$

with $\theta_{2}^{\mathrm{b}}=-\theta_{1}^{\mathrm{b}}$. Then, $x_{\text {reach }}^{\mathrm{b}}-x_{2}^{\mathrm{b}}$ is given by

$$
x_{\text {reach }}^{\mathrm{b}}-x_{2}^{\mathrm{b}}=\frac{\theta_{3}^{\mathrm{b}}-\theta_{2}^{\mathrm{b}}}{c_{0}},
$$

with

$$
\theta_{3}^{\mathrm{b}}=-\sqrt{\theta_{2}^{\mathrm{b}^{2}}-2 c_{0} z_{\mathrm{b}}} .
$$

Finally, the distance $x_{\text {reach }}^{\mathrm{b}}$ is expressed with respect to the antenna height, the trapping layer base height, and the elevation angle, as

$$
x_{\text {reach }}^{\mathrm{b}}=2 \theta_{1}^{\mathrm{b}}\left(\frac{1}{c_{0}}-\frac{1}{c_{2}}\right)-\frac{\theta_{0}^{\mathrm{b}}+\theta_{\mathrm{ant}}}{c_{0}},
$$

with

$$
\theta_{\mathrm{ant}}=\sqrt{\theta_{0}^{\mathrm{b}^{2}}-2 c_{0} h_{\mathrm{ant}}} .
$$

2) Antenna inside the trapping layer: The antenna height is greater than the trapping layer base height. In this condition, the ray follows a trajectory as depicted in figure 3. Similarly to the previous case,

$$
\begin{aligned}
x_{\text {reach }}^{\mathrm{i}} & =x_{1}^{\mathrm{i}}+\left(x_{2}^{\mathrm{i}}-x_{1}^{\mathrm{i}}\right)+\left(x_{\text {reach }}^{\mathrm{i}}-x_{2}^{\mathrm{i}}\right), \\
& =\theta_{2}^{\mathrm{i}} \frac{c_{0}-c_{2}}{c_{0} c_{2}}+\frac{\theta_{3}^{\mathrm{i}}}{c_{0}}-\frac{\theta_{0}^{\mathrm{i}}}{c_{2}},
\end{aligned}
$$




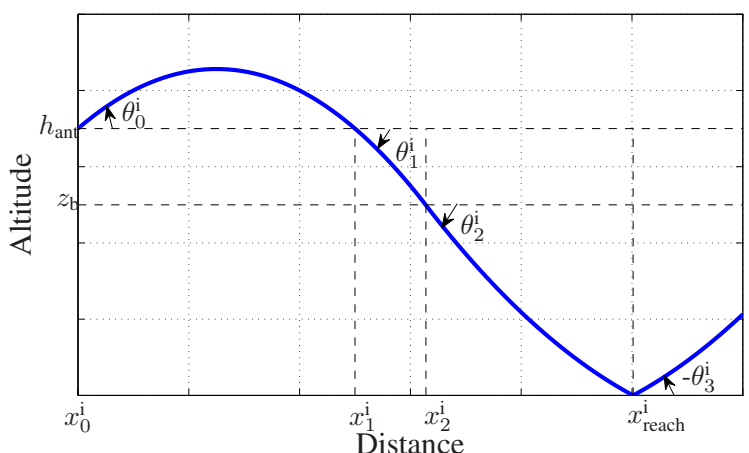

Fig. 3. Trajectory of a ray in the presence of a trilinear duct with a trapping layer of base height $z_{\mathrm{b}}$ and infinite thickness, case $h_{\mathrm{ant}}>z_{\mathrm{b}}$.

with

$$
\begin{aligned}
\theta_{1}^{\mathrm{i}} & =-\theta_{0}^{\mathrm{i}}, \\
\theta_{2}^{\mathrm{i}} & =-\sqrt{\theta_{0}^{\mathrm{i}^{2}}-2 c_{2}\left(h_{\mathrm{ant}}-z_{\mathrm{b}}\right)}, \\
\text { and } \theta_{3}^{\mathrm{i}} & =-\sqrt{\theta_{0}^{\mathrm{i}^{2}}-2 c_{2} h_{\mathrm{ant}}-2\left(c_{0}-c_{2}\right) z_{\mathrm{b}}} .
\end{aligned}
$$

\section{B. Trilinear duct}

A trilinear duct is considered, as represented in figure 4, with $z_{\mathrm{t}}$ the trapping layer thickness. The values $H$ and $z_{H}$ are defined, respectively, by

$$
\begin{aligned}
& H=z_{\mathrm{t}}\left(1-\frac{c_{2}}{c_{0}}\right), \\
& z_{H}=z_{\mathrm{b}}+z_{\mathrm{t}}-H .
\end{aligned}
$$

For the elevated duct (figure 4a) $H$ is the duct thickness, and $z_{H}$ is the duct base height. For the surface-based duct (figure $4 \mathrm{~b}), z_{H}$ is defined by continuity as the negative height at which the refractivity would be the same as at altitude $z_{\mathrm{b}}+z_{\mathrm{t}}$. In this case, the duct thickness is $z_{\mathrm{b}}+z_{\mathrm{t}}$.

Unlike the infinite thickness case, some rays do not reach the surface in this configuration: they are not trapped. The ray that reaches the ground with the minimum elevation angle is considered.

1) Antenna below the trapping layer: We suppose $z_{\mathrm{b}}>$ $h_{\text {ant }}$, see figure 5 . The elevation angle $\theta_{0}^{\mathrm{b}}$ is fixed. For $z_{\mathrm{b}}$ and $c_{2}$ fixed, $z_{\mathrm{t}_{0}}$ denotes the limit trapping layer thickness from which the ray is trapped. This is the ray for which the angle $\theta_{12}^{\mathrm{i}}$ is null.

Eqs. (3) and (4) are still valid. Now,

$$
\theta_{12}^{\mathrm{b}}=\sqrt{\theta_{1}^{\mathrm{b}^{2}}+2 c_{2} z_{\mathrm{t} 0}}=0 .
$$

Finally, the limit trapping layer thickness $z_{\mathrm{t}_{0}}$ is expressed as

$$
z_{\mathrm{t} 0}^{\mathrm{b}}=-\frac{\theta_{0}^{\mathrm{b}^{2}}+2 c_{0}\left(z_{\mathrm{b}}-h_{\mathrm{ant}}\right)}{2 c_{2}} .
$$

Note that if $\theta_{0}^{\mathrm{b}}<0$, the above results are the same, since the ray reaches the interface at $z_{\mathrm{b}}$ with the angle $-\theta_{0}^{\mathrm{b}}$ after a bound on the ground.

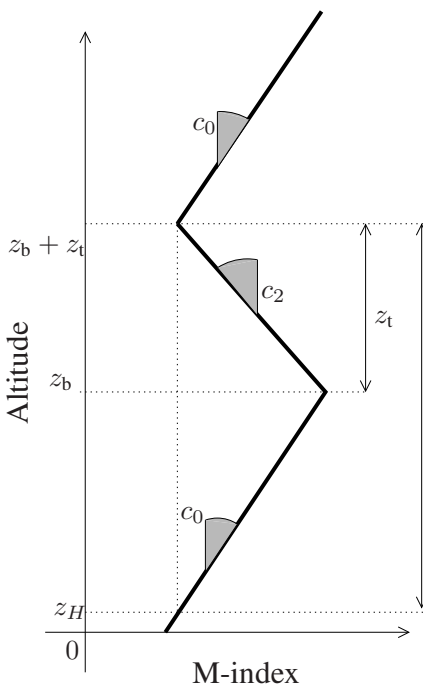

(a) Elevated duct

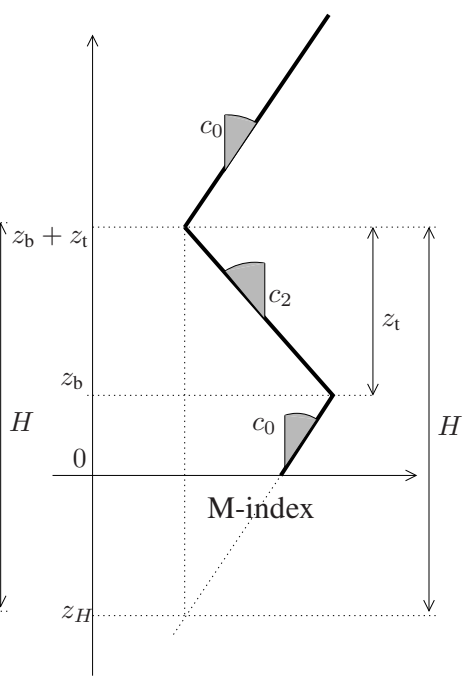

(b) Surface-based duct
Fig. 4. The trilinear ducts.

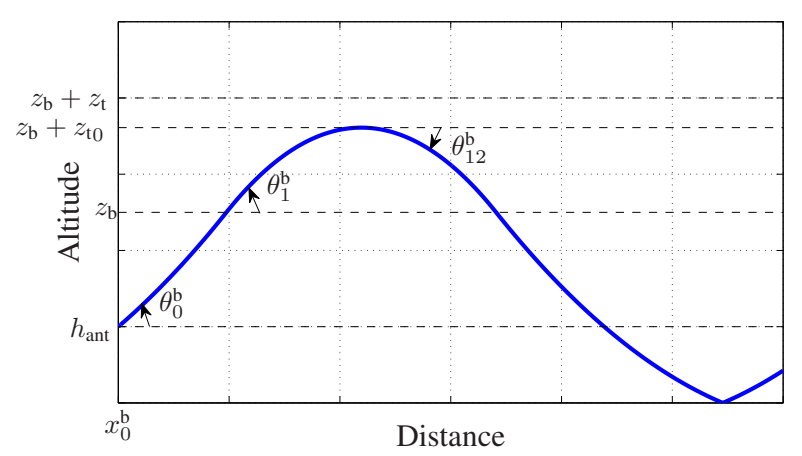

Fig. 5. Trajectory of a ray trapped in a trilinear duct with a trapping layer of base height $z_{\mathrm{b}}$ and thickness $z_{\mathrm{t}}$. Case $h_{\mathrm{ant}}<z_{\mathrm{b}}$. The same trapping layer of thickness $z_{\mathrm{t} 0}$ would have trapped the ray the same way.

2) Antenna inside the trapping layer: If the antenna is inside the trapping layer (i.e. $z_{\mathrm{b}}<h_{\mathrm{ant}}<z_{\mathrm{b}}+z_{\mathrm{t}}$ ), the configuration can be represented as in figure 6 . The angle $\theta_{12}^{\mathrm{i}}$ is expressed as

$$
\theta_{12}^{\mathrm{i}}=\sqrt{\theta_{0}^{\mathrm{i}}{ }^{2}+2 c_{2}\left(z_{\mathrm{b}}+z_{\mathrm{t} 0}-h_{\mathrm{ant}}\right)}=0,
$$

which yields

$$
z_{\mathrm{t}_{0}}^{\mathrm{i}}=-\frac{\theta_{0}^{\mathrm{i}^{2}}}{-2 c_{2}}-\left(z_{\mathrm{b}}-h_{\mathrm{ant}}\right) .
$$

The above results are consistent with $\theta_{0}^{\mathrm{i}}<0$.

\section{RETRIEVABLE DuctS FOR RFC SyStems}

In this section, parameter-based rules are given for the identification of the retrievable trilinear ducts.

From the study of section II, limits can be defined about the ducts retrievable by an RFC system. For instance, we can assume that the energy transmitted by the radar is in $\left[-\theta_{6 \mathrm{~dB}} / 2, \theta_{6 \mathrm{~dB}} / 2\right]$. In the case of a Gaussian aperture, $75 \%$ of 


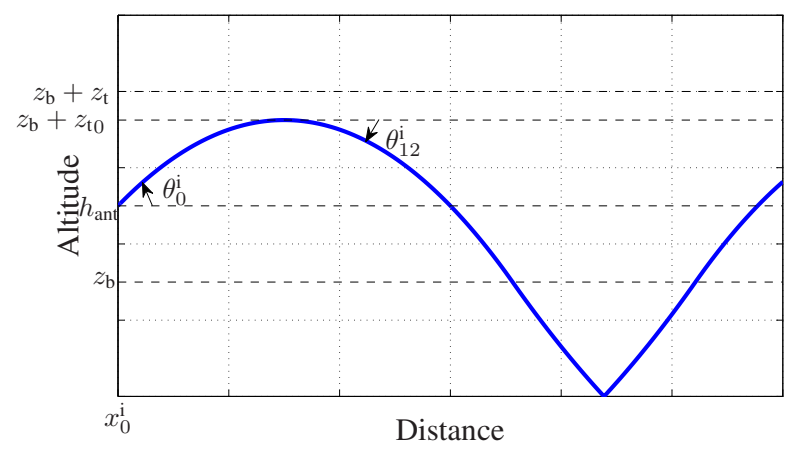

Fig. 6. Trajectory of a ray trapped in a trilinear duct with a trapping layer of base height $z_{\mathrm{b}}$ and thickness $z_{\mathrm{t}}$. Case $h_{\mathrm{ant}}>z_{\mathrm{b}}$. The same trapping layer of thickness $z_{\mathrm{t} 0}$ would have trapped the ray the same way.

the energy in contained in this interval. The elevation angle is denoted $\theta_{\mathrm{el}}$. Then, the initial angle of the considered rays $\theta_{0}$ is in $\left[\theta_{\mathrm{el}}-\theta_{6 \mathrm{~dB}} / 2, \theta_{\mathrm{el}}+\theta_{6 \mathrm{~dB}} / 2\right]=\left[\theta_{\min }, \theta_{\max }\right]$. In the following, $\theta_{\mathrm{el}}$ is supposed $\geq 0$, then $\left|\theta_{\max }\right| \geq\left|\theta_{\min }\right|$.

First of all, for the first mode to be guided into a trilinear duct such that $z_{\mathrm{b}} \neq 0$ at frequency $f$, it must satisfy [24]

$$
f \geq 265 \frac{c}{H \sqrt{\Delta M}}
$$

with $c$ the light velocity in the propagating medium (in $\mathrm{m} \cdot \mathrm{s}^{-1}$ ) and $\Delta M=-z_{\mathrm{t}} c_{2}$ the $\mathrm{M}$-index deficit into the trapping layer in M-unit. $H$ (in m) is defined by eq. (14). $f$ is in Hz. In the case of a surface-based duct such that $z_{\mathrm{b}}=0$, this condition becomes

$$
f \geq 398 \frac{c}{z_{\mathrm{t}} \sqrt{\Delta M}}
$$

where $z_{\mathrm{t}}$ is in $\mathrm{m}$.

We suppose that this condition is fulfilled in the following study. Indeed, except for very weak ducts, the order of magnitude of the minimum frequency is below $1 \mathrm{GHz}$, whereas RFC systems are considered to operate at more than $2 \mathrm{GHz}$. Below $2 \mathrm{GHz}$, the duct effect is hardly significant enough for performing RFC [25].

\section{A. Rules on $z_{t}$}

The rules on $z_{\mathrm{t}}$ are defined with respect to the ray study inside the trapping layer. However, rays are not sufficient to extensively describe the wave behaviour. In the trapping layer, caustics appear and reach its upper and lower parts [26], [27]. The energy is focused at the vicinity of the caustics (a phenomenon known as "edge focusing" [28]). Then, the ray of elevation $\theta_{\max }$ corresponds to a field of high intensity at the upper and lower parts of the trapping layer.

At the top of the trapping layer, some energy focused at the caustic is diffracted above the trapping layer. This is not taken into account by the ray study. However, this is of no consequence except that the value $z_{t_{\max }}$ could be slightly decreased if this phenomenon was extensively described.

We suppose a trilinear duct, with a trapping layer base height $z_{\mathrm{b}}$ and refractivity slope $c_{2}$ fixed. The antenna param- eters are known. From eqs. (17) and (19), we define $z_{t_{\max }}$ as

$$
z_{\operatorname{tmax}}= \begin{cases}-\frac{\theta_{\max }^{2}+2 c_{0}\left(z_{\mathrm{b}}-h_{\mathrm{ant}}\right)}{2 c_{2}} & \text { if } h_{\mathrm{ant}}<z_{\mathrm{b}}, \\
-\frac{\theta_{\max }^{2}}{-2 c_{2}}-\left(z_{\mathrm{b}}-h_{\mathrm{ant}}\right) & \text { if }\left\{\begin{array}{l}
z_{\mathrm{b}}<h_{\mathrm{ant}}, \\
h_{\mathrm{ant}}<z_{\mathrm{b}}+z_{\mathrm{t}} .
\end{array}\right.\end{cases}
$$

For fixed $z_{\mathrm{b}}$ and $c_{2}$, and $z_{\mathrm{t}}=z_{\mathrm{t} \max }$, all the energy transmitted by the radar is trapped in the duct. Consequently, if the trapping layer is thicker than the defined limit $\left(z_{\mathrm{t}}>z_{\mathrm{tmax}}\right)$, the effect of the duct is the same: all the energy is trapped by the trapping layer. Then, let $\left(z_{\mathrm{b} 1}, c_{21}, z_{\mathrm{t} 1}\right)$ and $\left(z_{\mathrm{b} 2}, c_{22}, z_{\mathrm{t} 2}\right)$ be two sets of parameters defining two surface-based ducts such that $z_{\mathrm{b} 1}=z_{\mathrm{b} 2}, c_{21}=c_{22}$, and $z_{\mathrm{t} 1} \neq z_{\mathrm{t} 2}$. An RFC system cannot discriminate the two ducts if $z_{\mathrm{t}_{1}} \geq z_{\mathrm{t}_{\max }}$ and $z_{\mathrm{t} 2} \geq z_{\mathrm{tmax}}$. (The energy at the sea level is the same.)

Edge focusing also occurs at the bottom of the trapping layer. This appears to be a problem since some energy reaches the ground whereas no rays do. A rule of thumb is introduced: we consider that a duct is not retrievable if no rays initially going upward $\left(\theta_{0} \geq 0\right)$ reach an altitude below the transmitting antenna $\left(z<h_{\mathrm{ant}}\right)$.

The value $z_{\mathrm{tmin}}$ is defined as

$$
z_{\mathrm{t} \text { min }}= \begin{cases}-\left(z_{\mathrm{b}}-h_{\mathrm{ant}}\right) \frac{c_{0}}{c_{2}} & \text { if } h_{\mathrm{ant}}<z_{\mathrm{b}}, \\ -z_{\mathrm{b}} \frac{c_{0}}{c_{2}} & \text { if } h_{\mathrm{ant}} \geq z_{\mathrm{b}} .\end{cases}
$$

The rule for $h_{\mathrm{ant}} \geq z_{\mathrm{b}}$ implies that the duct is a surface-based duct and not an elevated duct (see figure 4). If the trapping layer is less thick than this limit $\left(z_{\mathrm{t}}<z_{\mathrm{tmin}}\right)$, no rays reach the ground level: the duct cannot be detected by an RFC system.

The rule for $h_{\mathrm{ant}}<z_{\mathrm{b}}$ reflects the fact that no ray going upward and trapped in the duct reach an altitude below the antenna. This rule is defined from eq. (17) with $\theta_{0}=0 \mathrm{rad}$.

\section{B. Rule on $z_{b}$}

Now, we consider that the ray reaches the ground $\left(z_{\mathrm{t}}>\right.$ $\left.z_{\text {tmin }}\right)$. The question is: does the ray reach the ground before the maximum radar range? Only the case of the antenna below the trapping layer is presented. When the antenna is above the trapping layer, the energy going downward is modified by the duct, that is consequently detectable at short range. From eq. (8), the angle $\theta_{1}$ is expressed as

$$
\theta_{1}=\frac{1}{2}\left[x_{\text {reach }}+\frac{\theta_{\max }+\theta_{\text {ant }}}{c_{0}}\right] \frac{c_{0} c_{2}}{c_{2}-c_{0}} .
$$

Now, if $x_{\max }$ denotes the maximum radar range, the maximum trapping layer base height $z_{\mathrm{b} \max }$ is expressed from (4) and (24) as

$$
z_{\mathrm{b} \max }=h_{\mathrm{ant}}-\frac{\theta_{\max }^{2}}{2 c_{0}}+\frac{1}{8} \frac{c_{2}^{2} c_{0}}{\left(c_{2}-c_{0}\right)^{2}}\left[x_{\max }+\frac{\theta_{\mathrm{max}}+\theta_{\mathrm{ant}}}{c_{0}}\right]^{2} .
$$

For any trapping layer such that $z_{\mathrm{b}}>z_{\mathrm{bmax}}$, almost no energy reaches the ground, and the RFC system sees no ducting condition. Note that $z_{\mathrm{bmax}}$ tends to infinity when $c_{2}$ tends to zero. It is consistent with the fact that an infinitely weak trapping layer would bend the wave to the sea level at infinity. 


\section{Numerical Results}

In this section, numerical results corresponding to the different rules are presented. They are performed by a split-step resolution of the parabolic wave equation. The sea surface is considered as smooth and perfectly conducting. This hypothesis is relevant in S-band with a sea state not too high. Indeed, with sea state 3 (wave height $h_{1 / 3} \approx 1 \mathrm{~m}$ ) at $3 \mathrm{GHz}$, and considering grazing angles $\left(\theta_{\mathrm{g}}<1^{\circ}\right)$, the Rayleigh criterion expressed as

$$
h_{1 / 3}<\frac{\lambda}{8 \sin \theta_{\mathrm{g}}}
$$

characterising the smooth surfaces (e.g. [29]) is barely fulfilled. For higher frequencies or rougher sea states, the surface roughness should be considered. The propagation factor is taken at $1 \mathrm{~m}$ high.

The sensitivity of the simulations is analysed with respect to the duct parameters in the cases of retrievable and nonretrievable ducts. The simulation parameters correspond to Wallops measurement campaign [11], except that the aperture is considered as Gaussian to fit the theoretical study. The maximum range $x_{\max }$ is set to $60 \mathrm{~km}$. The antenna works at $2.84 \mathrm{GHz}$. It is $30.78 \mathrm{~m}$ high with a $3 \mathrm{~dB}$ aperture beamwidth of $0.4^{\circ} . \theta_{\max }$ is chosen equal to $\theta_{6 \mathrm{~dB}} / 2$ such that $75 \%$ of the energy is confined into a cone $\left[-\theta_{6 \mathrm{~dB}} / 2, \theta_{6 \mathrm{~dB}} / 2\right]$.

To compare two propagation factors $\mathbf{x}$ and $\mathbf{y}$ expressed in natural values, two different distances are considered. $\mathrm{RMS}_{\text {nat }}(\mathbf{x}, \mathbf{y})$ denotes the root mean square between the two vectors. $\operatorname{RMS}_{\mathrm{dB}}(\mathbf{x}, \mathbf{y})=\operatorname{RMS}_{\text {nat }}\left(10 \log _{10}(\mathbf{x}), 10 \log _{10}(\mathbf{y})\right)$ denotes the root mean square between the vectors $\mathbf{x}$ and $\mathbf{y}$ expressed in $\mathrm{dB}$. Indeed, propagation factors are classically expressed in $\mathrm{dB}$ for $\mathrm{RFC}$ and more generally in the propagation community.

The key idea of the following simulations is to compare the distance between two clutter returns for two close ducts, in the case of retrievable and non-retrievable ducts. The aim is to show that when the rules defined in section III are not fulfilled $\left(z_{\mathrm{b}}>z_{\mathrm{b} \max }, z_{\mathrm{t}}>z_{\mathrm{tmax}}\right.$, or $\left.z_{\mathrm{t}}<z_{\mathrm{tmin}}\right)$, the variation of the out-of-bound parameter has a very low impact on the clutter return.

\section{A. Retrievable duct}

For this first simulation, a duct of which the parameters are far from the defined limits is considered. The trapping layer base height, refractivity slope into the trapping layer, and trapping layer thickness are $z_{\mathrm{b}}=10 \mathrm{~m}, c_{2}=-0.2 \mathrm{M}$ unit. $\mathrm{m}^{-1}$, and $z_{\mathrm{t}}=40 \mathrm{~m}$, respectively. The $2 \mathrm{D}$ propagation factor with respect to distance and altitude is represented in figure 7 . The M-index is also plotted with respect to altitude.

The limits for the retrievable ducts can be calculated. There is no condition of the trapping layer base height since eq. (25) gives a value of $z_{\mathrm{b} \max }$ less than the antenna height. Following (23), the minimum trapping layer thickness is $z_{\mathrm{t}_{\text {min }}} \approx 5.9 \mathrm{~m}$ and following (22), the maximum trapping layer thickness is $z_{\mathrm{t}_{\text {max }}} \approx 143 \mathrm{~m}$.

To test the variability of the simulation with the duct parameters, the propagation factor at the sea level $(z=1 \mathrm{~m})$ is plotted for the considered duct and 4 other ducts, see figure 8 .

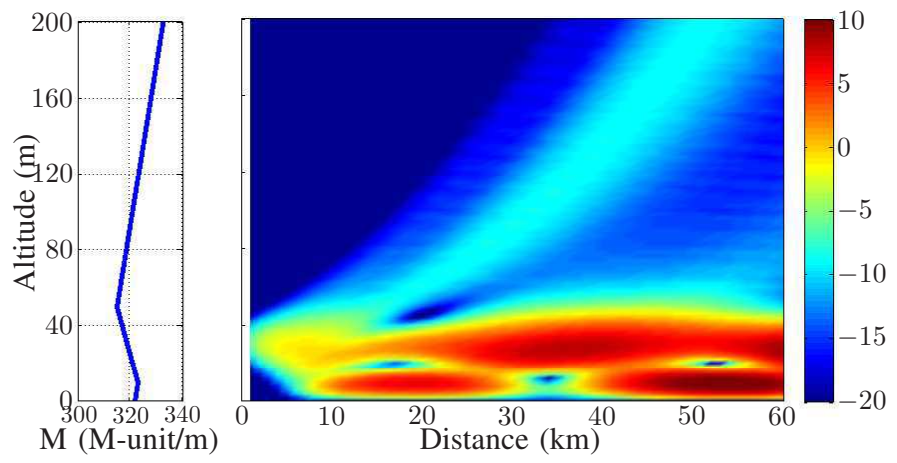

Fig. 7. Left, modified refractivity with respect to altitude for $z_{\mathrm{b}}=10 \mathrm{~m}$, $c_{2}=-0.2$ M-unit.m ${ }^{-1}, z_{\mathrm{t}}=40 \mathrm{~m}$. Right, corresponding propagation factor at $2.84 \mathrm{GHz}$.

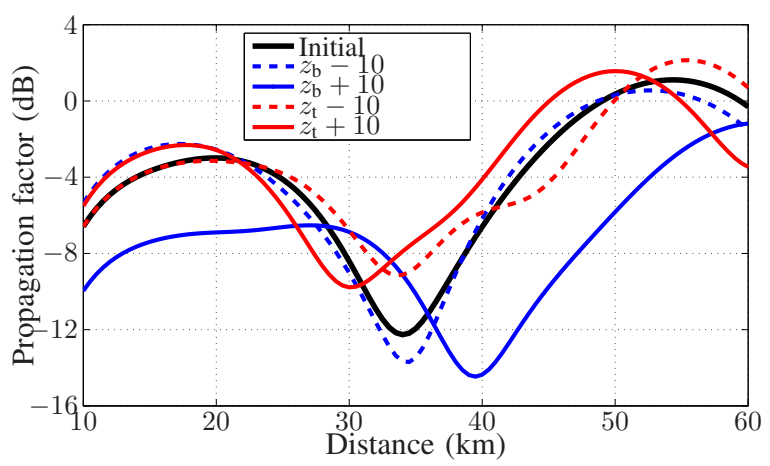

Fig. 8. Propagation factors at the sea level with respect to the distance at 2.84 $\mathrm{GHz}$ for the initial refractivity profile $z_{\mathrm{b}}=10 \mathrm{~m}, c_{2}=-0.2 \mathrm{M}$-unit.m $^{-1}$, $z_{\mathrm{t}}=40 \mathrm{~m}$ (black), for $z_{\mathrm{b}}=0 \mathrm{~m}$ (dotted blue), for $z_{\mathrm{b}}=20 \mathrm{~m}$ (blue), for $z_{\mathrm{t}}=30 \mathrm{~m}$ (dotted red), and for $z_{\mathrm{t}}=50 \mathrm{~m}$ (red).

These ducts correspond to a modification on $z_{\mathrm{b}}$ of $-10 \mathrm{~m}$ and $+10 \mathrm{~m}$, in dotted blue and continuous blue, and a modification on $z_{\mathrm{t}}$ of $-10 \mathrm{~m}$ and $+10 \mathrm{~m}$, in dotted red and continuous red, respectively. The 4 considered modifications in the vertical Mprofile modify the simulated propagation factor. The decrease of $z_{\mathrm{b}}$ has the less impact, certainly because $z_{\mathrm{b}}$ is already small in the initial configuration. However, each modification of a parameter has a significant impact on the propagation factor.

The RMS distances are calculated. When $z_{\mathrm{t}}$ varies, it gives

- $\operatorname{RMS}_{\mathrm{dB}}\left(\mathbf{P}_{\text {init }}, \mathbf{P}_{z_{\mathrm{t}}-10}\right)=2.12$;

- $\operatorname{RMS}_{\text {nat }}\left(\mathbf{P}_{\text {init }}, \mathbf{P}_{z_{\mathrm{t}}-10}\right)=1.12$;

- $\operatorname{RMS}_{\mathrm{dB}}\left(\mathbf{P}_{\text {init }}, \mathbf{P}_{z_{\mathrm{t}}+10}\right)=1.37$;

- $\mathrm{RMS}_{\text {nat }}\left(\mathbf{P}_{\text {init }}, \mathbf{P}_{z_{\mathrm{t}}+10}\right)=6.90 \times 10^{-1}$.

When $z_{\mathrm{b}}$ varies,

- $\mathrm{RMS}_{\mathrm{dB}}\left(\mathbf{P}_{\text {init }}, \mathbf{P}_{z_{\mathrm{b}}-10}\right)=1.52$;

- $\mathrm{RMS}_{\text {nat }}\left(\mathbf{P}_{\text {init }}, \mathbf{P}_{z_{\mathrm{b}}-10}\right)=9.45 \times 10^{-1}$;

- $\mathrm{RMS}_{\mathrm{dB}}\left(\mathbf{P}_{\text {init }}, \mathbf{P}_{z_{\mathrm{b}}+10}\right)=3.09$;

- $\operatorname{RMS}_{\text {nat }}\left(\mathbf{P}_{\text {init }}, \mathbf{P}_{z_{\mathrm{b}}+10}\right)=1.25$.

This gives the order of magnitude of the variability of the propagation factor for a retrievable duct.

\section{B. Non-retrievable duct: $z_{t}>z_{\text {tmax }}$}

This example illustrates that for a value of the trapping layer thickness $z_{\mathrm{t}}$ greater than $z_{\mathrm{tmax}}$, the propagation factor at the 

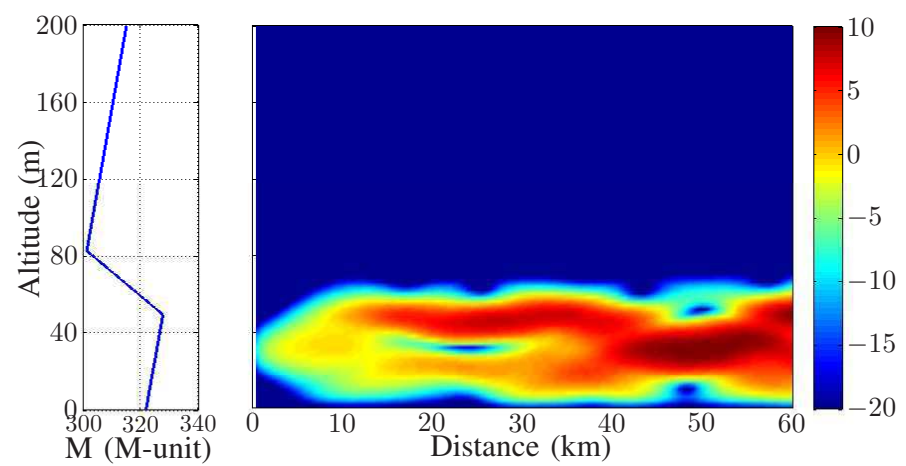

Fig. 9. Left, modified refractivity with respect to altitude for $z_{\mathrm{b}}=50 \mathrm{~m}$, $c_{2}=-0.8$ M-unit.m ${ }^{-1}, z_{\mathrm{t}}=33 \mathrm{~m}$. Right, corresponding propagation factor at $2.84 \mathrm{GHz}$.

sea level is the same as for $z_{\mathrm{t}}=z_{\mathrm{tmax}}$. The trapping layer parameters for this examples are $z_{\mathrm{b}}=50 \mathrm{~m}, c_{2}=-0.8 \mathrm{M}$ unit.m ${ }^{-1}, z_{\mathrm{t}}=33 \mathrm{~m}$. Indeed, for $z_{\mathrm{b}}=50 \mathrm{~m}$ and $c_{2}=-0.8 \mathrm{M}$ unit.m ${ }^{-1}$, eq. (22) gives $z_{\mathrm{tmax}} \approx 33 \mathrm{~m}$.

In figure 9 , the propagation factor with respect to distance and altitude is plotted. We observe that almost all the energy is trapped by the trapping layer, which is consistent with $z_{\mathrm{t}}=$ $z_{\text {tmax }}$.

In figure 10, the propagation factor at the sea level simulated for the foregoing duct (called "Initial" in the legend) is plotted. The propagation factors corresponding to a modification on $z_{\mathrm{b}}$ of $-10 \mathrm{~m}$ and $+10 \mathrm{~m}$, and to a modification on $z_{\mathrm{t}}$ of $-10 \mathrm{~m}$ and $+10 \mathrm{~m}$, are also plotted in dotted blue and continuous blue, and in dotted red and continuous red, respectively.

The variation of the trapping layer base height has a significant impact on the propagation factor. As for the trapping layer thickness, the propagation factor corresponding to $z_{\mathrm{t}}=z_{\mathrm{t} \max }+10 \mathrm{~m}$ coincides with $z_{\mathrm{t}}=z_{\mathrm{tmax}}$. The one corresponding to $z_{\mathrm{t}}=z_{\mathrm{t} \max }-10 \mathrm{~m}$ is barely distinguishable. In RMS values, when the trapping layer thickness $z_{\mathrm{t}}$ varies, it gives

- $\operatorname{RMS}_{\mathrm{dB}}\left(\mathbf{P}_{\text {init }}, \mathbf{P}_{z_{\mathrm{t}}-10}\right)=2.32 \times 10^{-1}$;

- $\mathrm{RMS}_{\text {nat }}\left(\mathbf{P}_{\text {init }}, \mathbf{P}_{z_{\mathrm{t}}-10}\right)=1.05 \times 10^{-1}$;

- $\operatorname{RMS}_{\mathrm{dB}}\left(\mathbf{P}_{\text {init }}, \mathbf{P}_{z_{\mathrm{t}}+10}\right)=3.04 \times 10^{-2}$;

- $\operatorname{RMS}_{\text {nat }}\left(\mathbf{P}_{\text {init }}, \mathbf{P}_{z_{\mathrm{t}}+10}\right)=1.31 \times 10^{-2}$.

When the trapping layer base height $z_{\mathrm{b}}$ varies,

- $\operatorname{RMS}_{\mathrm{dB}}\left(\mathbf{P}_{\text {init }}, \mathbf{P}_{z_{\mathrm{b}}-10}\right)=4.72$;

- $\operatorname{RMS}_{\text {nat }}\left(\mathbf{P}_{\text {init }}, \mathbf{P}_{z_{\mathrm{b}}-10}\right)=1.83$;

- $\operatorname{RMS}_{\mathrm{dB}}\left(\mathbf{P}_{\text {init }}, \mathbf{P}_{z_{\mathrm{b}}+10}\right)=4.58$;

- $\mathrm{RMS}_{\text {nat }}\left(\mathbf{P}_{\text {init }}, \mathbf{P}_{z_{\mathrm{b}}+10}\right)=1.35$.

Note that the RMS for $z_{\mathrm{t}}=z_{\mathrm{t} \text { max }}+10 \mathrm{~m}$ and $z_{\mathrm{t}}=z_{\mathrm{t} \text { max }}-10 \mathrm{~m}$ have one order of magnitude of difference, even if they are visually hard to differentiate.

So, when $z_{\mathrm{t}}$ is close to or greater than $z_{\mathrm{tmax}}$, an RFC system cannot quantify it since it has no impact on the propagation factor at the sea level. The prediction of the $2 \mathrm{D}$ propagation with $z_{\mathrm{t}}>z_{\mathrm{t} \max }$ would still be right because a trapping layer thicker than $z_{\mathrm{tmax}}$ gives the same $2 \mathrm{D}$ propagation factor.

A problem appears when the retrieved duct is used as an input for simulations at different frequencies or wider apertures. The uncertainty on the trapping layer thickness

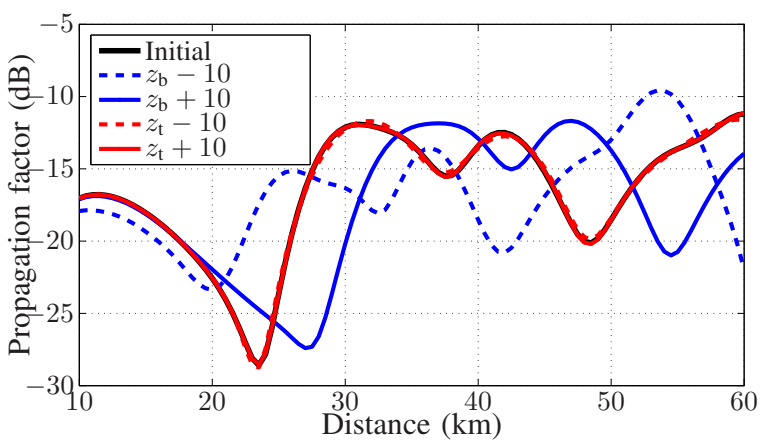

Fig. 10. Propagation factors at the sea level with respect to the distance at $2.84 \mathrm{GHz}$ for the initial refractivity profile $z_{\mathrm{b}}=50 \mathrm{~m}, c_{2}=-0.8 \mathrm{M}$ unit.m ${ }^{-1}, z_{\mathrm{t}}=33 \mathrm{~m}$ (black), for $z_{\mathrm{b}}=40 \mathrm{~m}$ (dotted blue), for $z_{\mathrm{b}}=60 \mathrm{~m}$ (blue), for $z_{\mathrm{t}}=23 \mathrm{~m}$ (dotted red), and for $z_{\mathrm{t}}=43 \mathrm{~m}$ (red).
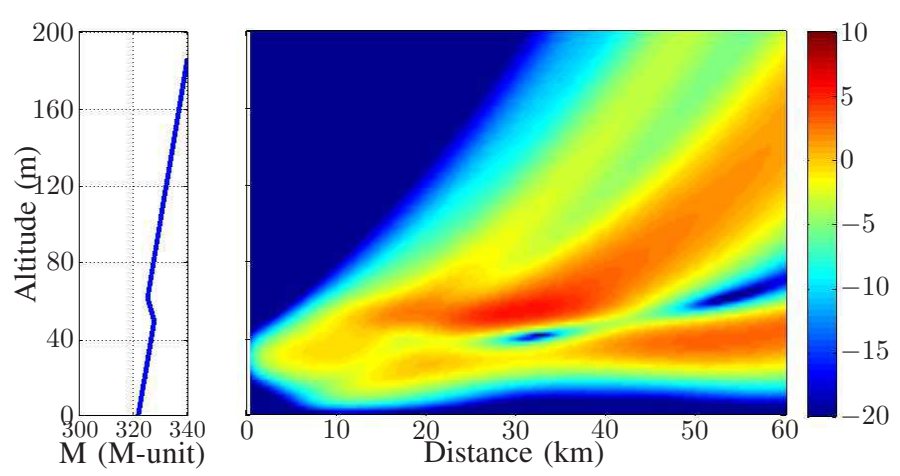

Fig. 11. Left, modified refractivity with respect to altitude for $z_{\mathrm{b}}=50 \mathrm{~m}$, $c_{2}=-0.2$ M-unit.m ${ }^{-1}, z_{\mathrm{t}}=12 \mathrm{~m}$. Right, corresponding propagation factor at $2.84 \mathrm{GHz}$.

$z_{\mathrm{t}}$ would imply that the propagation simulation could not be trusted. Moreover, the user must be aware that the illposedness in this case corresponds to a physical indeterminacy, not to a problem in the inversion algorithm.

\section{Non-retrievable duct: $z_{t}<z_{\text {tmin }}$}

In this section, the chosen example highlights the fact that for a too thin trapping layer, the energy is not trapped, and it barely modifies the propagation factor at sea level. This makes these ducts hard to retrieve by RFC. The trapping layer initial parameters for this example are $z_{\mathrm{b}}=50 \mathrm{~m}, c_{2}=-0.2 \mathrm{M}$ unit.m ${ }^{-1}, z_{\mathrm{t}}=12 \mathrm{~m}$. Indeed, for $z_{\mathrm{b}}=50 \mathrm{~m}$ and $c_{2}=-0.2 \mathrm{M}$ unit.m ${ }^{-1}$, eq. (23) gives $z_{\mathrm{tmin}} \approx 12 \mathrm{~m}$.

The corresponding 2D propagation factor is plotted in figure 11. We see that the energy trapped in the duct does not reach the ground. We focus on the signal at the sea level, in black in figure 12. The propagation factors corresponding to a modification on $z_{\mathrm{b}}$ of $-10 \mathrm{~m}$ and $+10 \mathrm{~m}$, in dotted blue and continuous blue, and to a modification on $z_{\mathrm{t}}$ of $-10 \mathrm{~m}$ and $+10 \mathrm{~m}$, in dotted red and continuous red, respectively.

At first sight, all the plots are easily distinguishable. This is due to the low values of the propagation factors. In dotted black, the level of the propagation factor at $10 \mathrm{~km}$ minus 20 $\mathrm{dB}$ is plotted. It can reasonably be chosen as an arbitrary noise level. In practice, this level depends on the sensitivity of the 


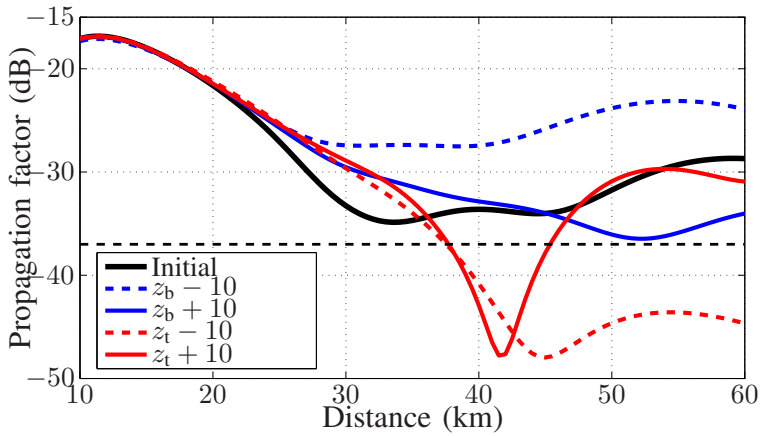

Fig. 12. Propagation factors at the sea level with respect to the distance at $2.84 \mathrm{GHz}$ for the initial refractivity profile $z_{\mathrm{b}}=50 \mathrm{~m}, c_{2}=-0.2 \mathrm{M}$ unit.m ${ }^{-1}, z_{\mathrm{t}}=12 \mathrm{~m}$ (black), for $z_{\mathrm{b}}=40 \mathrm{~m}$ (dotted blue), for $z_{\mathrm{b}}=60 \mathrm{~m}$ (blue), for $z_{\mathrm{t}}=2 \mathrm{~m}$ (dotted red), and for $z_{\mathrm{t}}=22 \mathrm{~m}$ (red).

radar and on the sea state, that affects the radar cross section of the sea surface.

At $z_{\mathrm{t}}=z_{\mathrm{tmin}}$, the signal is slightly above the noise level. When $z_{\mathrm{t}}=z_{\mathrm{tmin}}-10 \mathrm{~m}$, the curve falls behind the sea level and differentiating the two signal requires a sensitive system. When $z_{\mathrm{t}}=z_{\mathrm{tmin}}+10 \mathrm{~m}$, the signal increases after $50 \mathrm{~km}$, which makes the duct more easily detectable.

When $z_{\mathrm{b}}=40 \mathrm{~m}$ and $c_{2}=-0.2$ M-unit.m ${ }^{-1}, z_{\mathrm{t} \text { min }} \approx$ $5.4 \mathrm{~m}$. Consequently, for $z_{\mathrm{t}}=12 \mathrm{~m}$, the duct is retrievable. In figure 12, it corresponds to the dotted blue curve, which is as expected above the noise level. When $z_{\mathrm{b}}=60 \mathrm{~m}$ and $c_{2}=-0.2$ M-unit.m ${ }^{-1}$ (continuous blue curve), $z_{\mathrm{t}_{\min }} \approx 17 \mathrm{~m}$. For $z_{\mathrm{t}}=12 \mathrm{~m}$, the duct is non retrievable if the noise is considered.

We focus now on the RMS values. When $z_{\mathrm{t}}$ varies,

- $\operatorname{RMS}_{\mathrm{dB}}\left(\mathbf{P}_{\text {init }}, \mathbf{P}_{z_{\mathrm{t}}-10}\right)=8.70$;

- $\mathrm{RMS}_{\text {nat }}\left(\mathbf{P}_{\text {init }}, \mathbf{P}_{z_{\mathrm{t}}-10}\right)=3.52 \times 10^{-2}$;

- $\operatorname{RMS}_{\mathrm{dB}}\left(\mathbf{P}_{\text {init }}, \mathbf{P}_{z_{\mathrm{t}}+10}\right)=4.02$;

- $\operatorname{RMS}_{\text {nat }}\left(\mathbf{P}_{\text {init }}, \mathbf{P}_{z_{\mathrm{t}}+10}\right)=2.31 \times 10^{-2}$.

When $z_{\mathrm{b}}$ varies, it gives

- $\operatorname{RMS}_{\mathrm{dB}}\left(\mathbf{P}_{\text {init }}, \mathbf{P}_{z_{\mathrm{b}}-10}\right)=5.74$;

- $\operatorname{RMS}_{\text {nat }}\left(\mathbf{P}_{\text {init }}, \mathbf{P}_{z_{\mathrm{b}}-10}\right)=1.13 \times 10^{-1}$;

- $\operatorname{RMS}_{\mathrm{dB}}\left(\mathbf{P}_{\text {init }}, \mathbf{P}_{z_{\mathrm{b}}+10}\right)=3.24$;

- $\operatorname{RMS}_{\text {nat }}\left(\mathbf{P}_{\text {init }}, \mathbf{P}_{z_{\mathrm{b}}+10}\right)=2.65 \times 10^{-2}$.

Note that non-retrievable ducts have a $\mathrm{RMS}_{\text {nat }}$ in the order of magnitude of $10^{-2}$.

\section{Non-retrievable duct: $z_{b}>z_{b \max }$}

This example illustrates the rule on the maximum trapping layer base height $z_{\mathrm{bmax}}$. The slope of the trapping layer $c_{2}$ is fixed at $-0.6 \mathrm{M}$-unit. $\mathrm{m}^{-1}$, and the trapping layer thickness $z_{\mathrm{t}}$ is chosen very large, $z_{\mathrm{t}}=100 \mathrm{~m}$ (see section III-B). In these conditions, $z_{\mathrm{bmax}} \approx 135 \mathrm{~m}$. In figure 13 the $2 \mathrm{D}$ propagation factor is shown for $z_{\mathrm{b}}=135 \mathrm{~m}, c_{2}=-0.6 \mathrm{M}$-unit. $\mathrm{m}^{-1}$, and $z_{\mathrm{t}}=100 \mathrm{~m}$. Note that the trapped energy barely reaches the sea level before the maximum range.

Figure 14 shows the influence of the trapping layer base height on the sea-level propagation factor when close to $z_{\mathrm{b} \max }$. In black, the propagation factor corresponding to $z_{\mathrm{bmax}}$ is plotted, in continuous blue the one corresponding to $z_{\mathrm{bmax}}+10 \mathrm{~m}$,

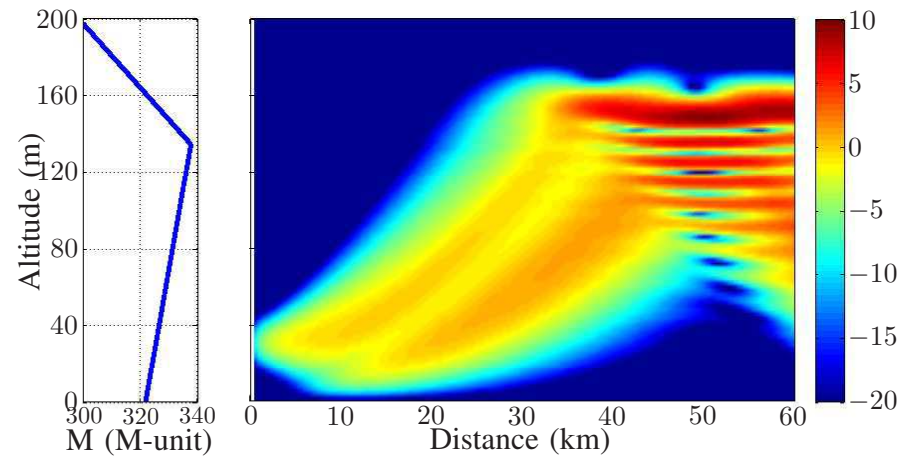

Fig. 13. Left, modified refractivity with respect to altitude for $z_{\mathrm{b}}=135 \mathrm{~m}$, $c_{2}=-0.6$ M-unit.m ${ }^{-1}, z_{\mathrm{t}}=100 \mathrm{~m}$. The top of the trapping layer $z_{\mathrm{b}}+z_{\mathrm{t}}$ is above $200 \mathrm{~m}$. Right, corresponding propagation factor at $2.84 \mathrm{GHz}$.

and in dotted blue the one corresponding to $z_{\mathrm{bmax}}-10 \mathrm{~m}$. The parameter $z_{\mathrm{t}}$ does not vary since it is chosen large enough to be $>z_{\text {tmax }}$, as stated in section III-B.

When $z_{\mathrm{b}}>z_{\mathrm{bmax}}$, the signal is not modified by the duct if the noise level is considered. Consequently, such a duct is non retrievable by any RFC system. When $z_{\mathrm{b}}<z_{\mathrm{bmax}}$, the propagation factor significantly increases after $55 \mathrm{~km}$, and the duct is detectable and potentially quantifiable. As for the study on $z_{\mathrm{tmin}}$, the threshold for defining a retrievable duct depends on the noise level, i.e. on the radar sensitivity and on the sea state.

When $z_{\mathrm{b}}$ varies, it gives

- $\operatorname{RMS}_{\mathrm{dB}}\left(\mathbf{P}_{\text {init }}, \mathbf{P}_{z_{\mathrm{b}}-10}\right)=7.19$;

- $\operatorname{RMS}_{\text {nat }}\left(\mathbf{P}_{\text {init }}, \mathbf{P}_{z_{\mathrm{b}}-10}\right)=4.20 \times 10^{-2}$;

- $\mathrm{RMS}_{\mathrm{dB}}\left(\mathbf{P}_{\text {init }}, \mathbf{P}_{z_{\mathrm{b}}+10}\right)=4.37$;

- $\mathrm{RMS}_{\text {nat }}\left(\mathbf{P}_{\text {init }}, \mathbf{P}_{z_{\mathrm{b}}+10}\right)=2.07 \times 10^{-3}$.

Here, the order of magnitude of the $\mathrm{RMS}_{\text {nat }}$ is $10^{-3}$ for the non-retrievable duct and $10^{-2}$ for the retrievable duct. The frontier between retrievable and non-retrievable duct is continuous, so one cannot expect sharp decisions. It is however far from the $\mathrm{RMS}_{\text {nat }}$ in the case of a fully retrievable duct (section IV-A).

From the two last examples, it comes out that the $\mathrm{RMS}_{\mathrm{dB}}$ distance favours the weak trapping layers. In operational conditions, an additive noise would cover the slight variations in the propagation factor. Consequently, the $\mathrm{RMS}_{\mathrm{dB}}$ distance is not adapted. Note that it is the distance used in all the previous RFC works.

\section{E. Application the the surface-based ducts from the 1998 Wallops Island measurement campaign}

Among the RFC works mentioned in the introduction, inversion methods are performed on measurements in the presence of evaporation ducts [18], [20] that are out of the main scope of this paper, or on the 1998 Wallops Island, VA measurement campaign in the presence of surface-based ducts [11], [12], [14]-[17], [19]. In this section, the rules presented in the paper are applied on the ducts from this measurement campaign.

A good overview of the ducts measured during this campaign can be seen in the figure 3 of [12], and the figure 


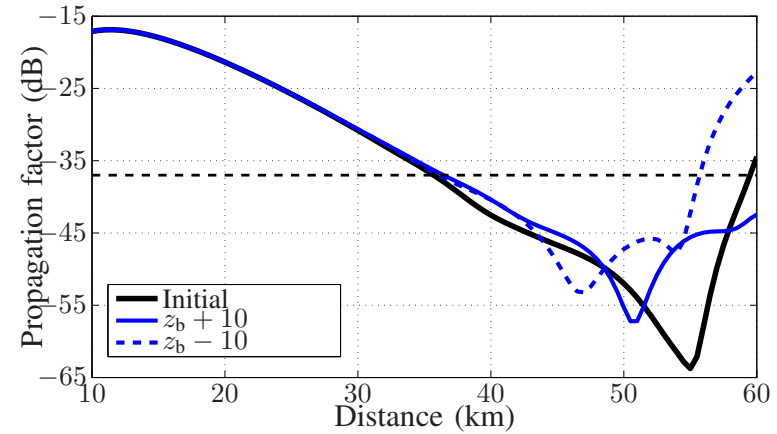

Fig. 14. Propagation factors at the sea level with respect to the distance at 2.84 $\mathrm{GHz}$ for the initial refractivity profile $z_{\mathrm{b}}=135 \mathrm{~m}, c_{2}=-0.6 \mathrm{M}$-unit.m $^{-1}$, $z_{\mathrm{t}}=100 \mathrm{~m}$ (black), for $z_{\mathrm{b}}=125 \mathrm{~m}$ (dotted blue), and for $z_{\mathrm{b}}=145 \mathrm{~m}$ (blue).

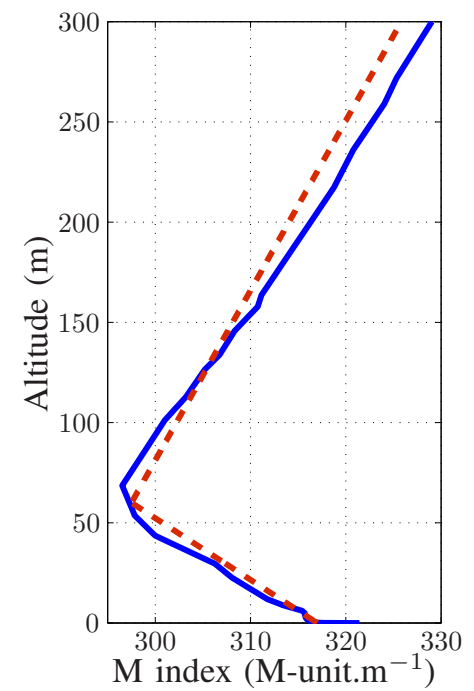

Fig. 15. An M-index profile with respect to altitude measured during the 1998 Wallops Island, VA measurement campaign (blue) and a close trilinear profile with $z_{\mathrm{b}}=0 \mathrm{~m}, c_{2}=-0.325 \mathrm{M}$-unit.m ${ }^{-1}, z_{\mathrm{t}}=60 \mathrm{~m}$ (dotted red).

9 of [17]. The ducts are close to each other, and a typical surface-based duct from the 1998 Wallops Island measurement campaign can be described with the following parameters: $z_{\mathrm{b}}=0 \mathrm{~m}, c_{2}=-0.325$ M-unit. $\mathrm{m}^{-1}, z_{\mathrm{t}}=60 \mathrm{~m}$. This corresponds to the measurement performed between 13:19 and 13:49 EST at the antenna, see figure 15. The working frequency is $2.84 \mathrm{GHz}$, the antenna height is $30.78 \mathrm{~m}$, and the radar aperture is $0.4^{\circ}$.

In these conditions, from (21), $f$ must be larger than $451 \mathrm{MHz}$. Moreover, $z_{\mathrm{b}_{\max }}=63.9 \mathrm{~m}$ and $z_{\mathrm{t}_{\min }}=0 \mathrm{~m}$. There is no rule on $z_{\mathrm{tmax}}$ since $h_{\mathrm{ant}}>z_{\mathrm{b}}+z_{\mathrm{t}}$. Thus, the measured ducts are far from the limits defined in this study. This is consistent with the fact that inverse methods have been performed with a good accuracy on these data. This confirms that the 1998 Wallops Island measurement campaign is appropriate for the validation of RFC techniques.

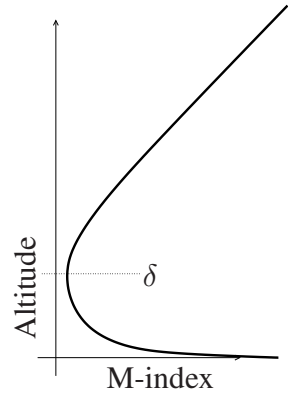

Fig. 16. The evaporation duct.

\section{Generalisation to Other Ducts}

In real conditions, the vertical refractivity profile is more complicated than a trilinear duct. However, note that the method exposed for the trilinear ducts can be applied to any duct described with a piecewise linear height dependency. Thus, the method is very general. Yet, the application to trilinear ducts gives a good overview of the retrievable ducts with analytic and simple formulas.

An evaporation duct at the sea surface is very common, that is why the previous rules are given is the case of a double duct (evaporation duct + surface-based duct) in this section. Let $\delta$ be the height of the evaporation duct (figure 16). Then, the modified refractivity is given by

$$
M(z)=M_{0}+0.125 z-0.125\left(\delta+z_{0}\right) \ln \left(\frac{z+z_{0}}{z_{0}}\right),
$$

for $z<2 \delta$. The surface roughness $z_{0}$ is considered equal to $1.5 \times 10^{-4} \mathrm{~m}$. From now on, $M_{\text {ant }}$ denotes $M\left(h_{\text {ant }}\right)$ and $M_{z}$ denotes $M(z)$ in general. Above this duct, a trilinear duct is supposed. $z_{\mathrm{b}}$ is considered greater than $\delta$.

The presence of an evaporation duct induces a new rule for the retrievable ducts, and modifies the previously stated ones. Note that for the evaporation duct to be significant, the frequency must satisfy condition (21), since the duct is at sea level.

\section{A. Evaporation duct rule}

For low antennas with low elevation angles in the presence of a strong evaporation duct, all the energy is trapped in the duct if $h_{\text {ant }}<\delta$ and $\theta_{\max }^{2}+2\left(M_{\delta}-M_{\text {ant }}\right)<0$ [25]. In this case, any surface-based duct above the evaporation duct is undetectable.

\section{B. Modified rule on $z_{t_{\max }}$ in the presence of an evaporation duct}

The surface-based duct is supposed to be above the evaporation duct.

1) Antenna above the evaporation duct: The considered ray reaches the duct with an unchanged angle and the waves trapped by the surface-based duct are the same. Thus, the rule on $z_{t_{\max }}$ is unchanged. However, the evaporation duct modifies the grazing angle, hence the magnitude of the clutter return is modified as well. 
2) Antenna inside the evaporation duct: To take into account the evaporation duct, one modification must be applied. If $z_{\mathrm{b}}>2 \delta$, in eq. (22), the maximum elevation angle $\theta_{\max }$ must be substituted by the angle $\theta_{2 \delta}$ such that

$$
\theta_{2 \delta}=\sqrt{\theta_{\max }^{2}+2 c_{\delta}\left(2 \delta-h_{\mathrm{ant}}\right)},
$$

where

$$
c_{\delta}=\frac{M_{2 \delta}+M_{\mathrm{ant}}}{2 \delta-h_{\mathrm{ant}}} .
$$

Hence $\theta_{2 \delta}$ is such that

$$
\theta_{2 \delta}=\sqrt{\theta_{\max }^{2}+2\left(M_{2 \delta}-M_{\mathrm{ant}}\right)} .
$$

Note that if $\theta_{\max }^{2}+2\left(M_{2 \delta}-M_{\mathrm{ant}}\right)<0$, the ray is trapped by the evaporation duct. No ray reaches the trapping layer that is consequently non retrievable.

If $\delta<z_{\mathrm{b}}<2 \delta$, the method is the same except that $M_{z_{\mathrm{b}}}$ must be used instead of $M_{2 \delta}$, and $\theta_{z_{\mathrm{b}}}$ instead of $\theta_{2 \delta}$.

\section{Modified rule on $z_{\text {tmin }}$ in the presence of an evaporation duct}

The rule on $z_{\mathrm{tmin}}$ is not modified by the presence of an evaporation duct. Indeed, this rule does not depend on the elevation angle.

\section{Modified rule on $z_{b \max }$ in the presence of an evaporation duct}

The definition of a new analytic rule on $z_{\mathrm{b}_{\max }}$ is difficult since it requires the horizontal length of the ray trajectory inside the evaporation duct. With the evaporation duct described by eq. (27), no analytic expression is available. Thus, a piecewise linear approximation of the duct [30], [31] is required. Then, the generalisation is easy with an iterative calculation on each linear piece of the refractivity profile.

\section{E. Generalised rule}

The rules exposed in this paper can be extended to any duct with a piecewise linear variation. An iterative algorithm on the number of linear pieces can give an analytic solution. However, the trilinear duct study gives a good approximation of the retrievable ducts with simple analytic formulations. For a higher number of parameters, a Monte-Carlo parametric study would also be an option.

\section{CONCLUSION}

This paper addresses the atmospheric ducts retrievable by refractivity from clutter (RFC). Non-retrievable ducts are defined as those for which a modification of one parameter of the duct does not change the measurable propagation factor at the sea level. In a first phase, only trilinear ducts constant with the distance are considered. The aim of this study is to show that an RFC system cannot retrieve all the atmospheric ducts, and to foresee which ones are non retrievable.

For fixed duct parameters, three values have been defined. They correspond to the minimum retrievable trapping layer thickness $z_{\mathrm{tmin}}$, eq. (23), the maximum retrievable trapping layer thickness $z_{\mathrm{tmax}}$, eq. (22), and the maximum retrievable trapping layer base height $z_{\mathrm{b}_{\max }}$, eq. (25). From these values, three rules have been stated:

- A trapping layer of thickness greater than the maximum thickness $\left(z_{\mathrm{t}}>z_{\mathrm{tmax}}\right)$ is considered as a trapping layer with a thickness equal to this maximum thickness $\left(z_{\mathrm{t}}=\right.$ $\left.z_{t_{\max }}\right)$.

- A trapping layer of thickness less than the minimum thickness $\left(z_{\mathrm{t}}<z_{\mathrm{tmin}}\right)$ is not considered (no trapping layer is detected by the RFC system).

- A trapping layer of base height greater than the maximum base height $\left(z_{\mathrm{b}}>z_{\mathrm{b} \max }\right)$ is not considered (no trapping layer is detected by the RFC system).

The value $z_{\mathrm{t} \max }$ only depends on geometric considerations. The values $z_{\mathrm{t} \text { min }}$ and $z_{\mathrm{b}_{\text {max }}}$ are harder to decide because they also depend on the radar sensitivity and on the sea state. Moreover, $z_{\mathrm{t}_{\text {min }}}$ also depends on the frequency on the RFC system.

This study can be summarized as follows. Once $z_{\mathrm{tmin}}(23)$, $z_{\mathrm{t} \max }(22), z_{\mathrm{b} \max }(25)$, and the minimum frequency $f_{\min }(20)$ or (21) have been defined, a trilinear duct is retrievable if and only if

- $f>f_{\min }$;

- $z_{\mathrm{b}}<z_{\mathrm{b} \max }$

- $z_{\mathrm{t} \text { min }}<z_{\mathrm{t}}<z_{\mathrm{t} \max }$.

An extension of the previous rules has been proposed in the presence of an evaporation duct. Then they can be extended to any piecewise linear profile. However, the results might be harder to interpret. The retrievable ducts can be analytically calculated with iterative algorithm, or decided after a parametric study with ray-tracing if the considered ducts are too complex.

It has also been shown that calculating the RMS difference between two propagation factors expressed in $\mathrm{dB}$ leads to overestimate the differences between two data with low received power. The RMS difference between the two propagation factors expressed in natural values seems more relevant.

The proposed method enhances the a priori knowledge of the capability of an RFC system. Combined with further investigations related to the type and parameters of clutter statistics, it could significantly improve the RFC systems. The ill-posedness due to non-retrievable ducts and ducts with similar effects can be identified. Last, such studies can help designing future RFC systems and measurement campaigns.

\section{ACKNOWLEDGMENT}

The authors would like to thank the French MoD for its financial support, and more particularly Yvonick Hurtaud from DGA-MI.

\section{REFERENCES}

[1] H. Jeske, Modern Topics in Microwave Propagation and Air-Sea Interaction. Dordrecht, Netherlands: D. Reidel, 1973, ch. State and limits of prediction methods for radar wave propagation conditions over the sea, pp. 130-148.

[2] S. M. Babin, G. S. Young, and C. J. A., "A new model of the oceanic evaporation duct," Journal of Applied Meteorology, vol. 36, pp. 193-204, 1997.

[3] Y. Hurtaud, C. Cochin, J. Claverie, and M. Aïdonidis, "Characterization of the maritime environment for systems performances assessments and for decision aid products in RF and EO wavebands," in Journées SEE OCOSS 2010, Brest, France, June 2010 
[4] G. LeFurjah, R. Marshall, T. Casey, T. Haack, and D. De Forest Boyer, "Synthesis of mesoscale numerical weather prediction and empirical site-specific radar clutter models," IET Radar Sonar Navig., vol. 4, pp. 747-754, 2010.

[5] K. D. Anderson, "Inference of refractivity profiles by satellite-to-ground RF measurements," Radio Science, vol. 17, pp. 653-663, 1982.

[6] L. Rogers, "Likelihood estimation of tropospheric duct parameters from horizontal propagation measurements," Radio Science, vol. 32, pp. 7992, 1997.

[7] D. F. Gingras, P. Gerstoft, and N. L. Gerr, "Electromagnetic matchedfield processing: Basic concepts and tropospheric simulations," IEEE Transactions on Antennas and Propagation, vol. 45, pp. 1536-1545, 1997.

[8] J. L. Krolik and J. Tabrikian, "Tropospheric refractivity estimation using radar clutter from the sea surface," in Battlespace Atmospheric Conference, Space and Nav. Warf. Syst. Cent., San Diego, Calif., 1997.

[9] P. Gerstoft, D. Gingras, L. Rogers, and W. Hodgkiss, "Estimation of radio refractivity structure using matched-field array processing," IEEE Transactions on Antennas and Propagation, vol. 48, pp. 345-356, 2000.

[10] X. Zhao, S. Huang, and H. Du, "Theoretical analysis and numerical experiments of variational adjoint approach for refractivity estimation," Radio Science, vol. 46, p. RS1006, 2011.

[11] L. T. Rogers, C. P. Hattan, and J. K. Stapleton, "Estimating evaporation duct heights from radar sea echo," Radio Science, vol. 35, pp. 955-966, 2000.

[12] P. Gerstoft, L. T. Rogers, J. L. Krolik, and W. S. Hodgkiss, "Inversion for refractivity parameters from radar sea clutter," Radio Science, vol. 38, p. 8053,2003

[13] C. Yardim, P. Gerstoft, and W. Hodgkiss, "Statistical maritime radar duct estimation using a hybrid genetic algorithm-Markov chain Monte Carlo method," Radio Science, vol. 42, p. RS3014, 2007.

[14] — , "Tracking refractivity from clutter using Kalman and particle filters," IEEE Transactions on Antennas and Propagation, vol. 56, pp. 1058-1070, 2008.

[15] R. Douvenot, V. Fabbro, P. Gerstoft, C. Bourlier, and J. Saillard, "A duct mapping method using least squares support vector machines," Radio Science, vol. 43, pp. 1-12, RS6005, 2008.

[16] R. Douvenot and V. Fabbro, "On the knowledge of radar coverage at sea using real time refractivity from clutter," IET Radar Sonar Navig., vol. 4, pp. 293-301, 2010.

[17] R. Douvenot, V. Fabbro, P. Gerstoft, C. Bourlier, and J. Saillard, "Real time refractivity from clutter using a best fit approach improved with physical information," Radio Science, vol. 45, p. RS1007, 2010.

[18] X.-F. Zhao and S.-X. Huang, "Estimation of atmospheric duct structure using radar sea clutter," Journal of the Atmospheric Sciences, vol. 69, pp. 2808-2818, 2012.

[19] A. Karimian, C. Yardim, P. Gerstoft, W. Hodgkiss, and A. Barrios, "Refractivity estimation from sea clutter: An invited review," Radio Science, vol. 46, p. RS6013, 2011.

[20] A. Karimian, C. Yardim, T. Haack, P. Gerstoft, W. Hodgkiss, and R. L. T., "Towards assimilation of atmospheric surface layer using numerical weather prediction and radar clutter observations," Journal of Applied Meteorology and Climatology, vol. 52, p. 23452355, 2013, 14 pp.

[21] J. R. Kuttler and D. G. Dockery, "Theoretical description of the parabolic approximation/Fourier split-step method of representing electromagnetic propagation in the troposphere," Radio Science, vol. 26, no. 2, pp. 381393, 1991.

[22] M. Levy, Parabolic Equation Methods for Electromagnetic Wave Propagation, ser. IEE electromagnetic waves 45, IET, Ed. IEE Electromagnetic Wave Series 45, 2000.
[23] L. M. Brekhovskikh, Waves in Layered Media. Academic Press, 1976.

[24] L. Boithias, Propagation des Ondes Radioélectriques dans l'Environnement Terrestre. Dunod, 1983, in French.

[25] R. A. Paulus, "Evaporation duct effects on sea clutter," IEEE Transactions on Antennas and Propagation, vol. 38, pp. 1765-1771, 1990.

[26] W. Munk and C. Wunsch, "Biases and caustics in long-range acoustic tomography," Deep-Sea Reasearch, vol. 32, pp. 1317-1346, 1985.

[27] Y. A. Kravtsov and Y. I. Orlov, Geometrical Optics of Inhomogeneous Media. Springer-Verlag, 1990.

[28] K. G. Budden, The Propagation of Radio Waves: The Theory of Radio Waves of Low Power in the Ionosphere and Magnetosphere. New York: Cambridge Univ. Press, 1988.

[29] A. Ishimaru, Wave Propagation and Scattering in Random Media. Wiley-IEEE Press, 1999.

[30] A. Kukushkin, Radio Wave Propagation in the Marine Boundary Layer. Wiley \& Sons, 2006

[31] T.-H. Chang, "Profile sampling dependence of the mlayer program," Ph.D. dissertation, Naval Postgraduate School, Monterey, California, March 1991.

Rémi Douvenot was born in Chartres, France, in 1982. He received the engineer degree from the ENAC (French National Civil Aviation School), the M.Sc. from Toulouse University, France, in 2005, and the Ph.D. degrees in electrical engineering from Nantes University, France, in 2008. His Ph.D. was on refractivity from clutter. In 2009, he worked with the Laboratoire des Signaux et Systèmes (L2S), UMR (SUPELEC - CNRS - Univ ParisSud) on non-destructive testing using eddy-currents. Since 2011, he has been lecturer in electromagnetics with TELECOM/EMA research group, ENAC. His research interests are the theory of wave propagation and refractivity from clutter.

Vincent Fabbro was born in Le Havre, France, in 1972. He received the Diplôme d'Études Approfondies (D.E.A) degrees from the École Nationale Supérieure de l'Aéronautique et de l'espace (SUPAERO), in 1995, and the $\mathrm{PhD}$ degrees in electronics from the Paul Sabatier University of Toulouse in 1999. He has been working since November 1999 for the Office National d'Etude et de Recherches Aérospatiales (ONERA) at the Electromagnetism and Radar Department where his research activities focus on modelling radiowave propagation effects for radar and telecommunication systems applications. $\mathrm{He}$ is currently the supervisor of PhDs on propagation modelling in troposphere and ionosphere.

Kevin Elis was born in Carcassonne, in 1982. He received the master degree from the Paul Sabatier University of Toulouse, France, in 2009, and the Ph.D. degrees in electromagnetism and high-frequency systems from the University of Toulouse, in 2012. From January 2013 to March 2013, he worked with TELECOM/EMA research group, ENAC (French National Civil Aviation School), on RFC and ray technics. Since April 2013, he has been an antenna engineer in the Antennas department of the CNES (French National Space Center), Toulouse. 